SALUD

Ciencias sociales

HUMANIDADES

TEMA DEL DÍA

COVID-19, UNA OPORTUNIDAD PARA REFLEXIONAR SOBRE LA TOMA DE DECISIONES EN INCERTIDUMBRE

- FRANCESC BORRELL I CARRIÓ 1

PENSAMIENTO ACTUAL

COVID-19. DIARIO DE LA EXPERIENCIA DESDE UNA UCI.

- TERESA LÓPEZ-SOBRINO

CUADERNO DE BITÁCORA COVID-19. IGUALADA 2020

- FRANCESC XAVIER CANTERO GÓMEZ 60

ARTE, SALUD Y SOCIEDAD

LAS INTELIGENCIAS DEL MÚSICO

- ESTEVE MOLERO 
Co-directores

Marc Antoni Broggi i Trias (PCBC)

Francesc Borrell (UB)

\section{Jefa de Redacción}

Núria Estrach (UAB)

\section{Consejo científico}

Juan Carlos Hernández Clemente

Juan Medrano Albéniz

Vicente Morales Hidalgo

\section{Correspondencia \\ Web:}

http://www.fundacionletamendi.com

Correo electrónico:

info@fundacionletamendi.com

\section{Envío de manuscritos:}

http://www.fundacionletamendi.com/revista-foliahumanistica/envio-de-manuscritos/

\section{Información editorial}

Folia Humanística publica artículos por encargo solicitados a especialistas, así como aquellas propuestas enviadas por los autores y aceptadas tras su evaluación por pares de académicos especializados.

Los textos recibidos se publicarán en la lengua original (castellano, catalán, inglés y francés); los que se consideren de relevancia mayor serán traducidos al inglés y castellano.

Los artículos deben ser originales y acompañados del documento "derechos de autor" que encontrarán en la web, junto a las normas de presentación a seguir.

Cada artículo publicado al final tendrá especificado la referencia de citación, donde se incluirá el número $\mathrm{DOI}{ }^{\circledR}$.

\section{Distribución}

La Revista Folia Humanística es de libre acceso a consultar online.

http://www.fundacionletamendi.com/category/rev

istal

Folia Humanística es una revista internacional que tiene el doble objetivo de fomentar, por un lado, la reflexión y el debate público en el ámbito de la Salud, Ciencias Sociales y Humanidades, y por el otro, la colaboración entre distintos equipos de investigación nacionales e internacionales que dinamicen el diálogo entre la filosofía de la medicina, la salud pública y la justicia social. Dividida en "Tema del día", (artículos para el debate), "Pensamiento actual", (artículos críticos de novedades editoriales), y "Arte, Salud y Sociedad", la revista se esfuerza en fortalecer las conexiones entre la investigación académica, la práctica clínica, las experiencias de los pacientes y sus implicaciones éticas y estéticas en la sociedad. Todo ello con la intención de favorecer la reflexión entre diferentes disciplinas sobre temas de actualidad y las tendencias más novedosas en el campo de las Humanidades y la Salud.

Folia Humanística is an International Journal, born with the dual aim of fuelling the discussion and public debate on issues of health, social sciences and humanities and on the hand, of fostering cooperation between various research groups, both national and International, to spur the dialogue between philosophy and medicine, public health and social justice. The Journal is divided into three different sections: "main focus" (article for debate), "Contemporary thought" (critical reviews of new Publications) and "Arts, Health and Society" which all contribute to strengthening the links between academic research, clinical practice, the experience of patients and their ethical and esthetical implications for society. Ultimately, the intention of the Journal is to promote reflection at the crossroads of several disciplines on topical issues and new trends in humanities and health. 


\title{
CUADERNO DE BITÁCORA COVID-19. IGUALADA 2020.
}

\section{Francesc Xavier Cantero Gómez}

\begin{abstract}
Resumen: Soy médico de familia. He nacido, resido y trabajo en Igualada, uno de los epicentros de la pandemia mundial por covid-19. En este artículo intentaré plasmar la situación de estos cuatro meses. Lo haré mediante las vivencias personales propias y de mis compañeros. Hablaré de cómo nos hemos organizado, de cómo hemos atendido a los pacientes con covid-19 y a los que no lo han tenido, cómo lo hemos vivido, qué hemos sentido.
\end{abstract}

Palabras clave: Médico de familia/ pandemia/ covid-19.

Abstract: COVID-19 LOGBOOK. IGUALADA 2020.

I am a family physician who was born in Igualada and currently live and work there. Igualada has been one of the epicenter of the global pandemic covid-19. In this article I will try to reflex what had happened this last four months. I will explain my personal and coworkers' experiences talking about how we have organized, how we assist all people with or without covid-19, how we lived and our feelings in this period of time.

Keywords: family physician/ pandemic/ covid-19.

Artículo recibido: 17 agosto 2020; aceptado: 1 setiembre 2020 .

\section{INTRODUCCIÓN}

¿Qué hemos aprendido con la pandemia por SARS-COV2? ¿Hemos centrado la atención en las personas o en la enfermedad? Seguramente somos más fuertes, pero ¿somos mejores profesionales, mejores personas? ¿La pandemia ha hecho que tengamos una sociedad mejor, más justa y equitativa? La Tierra, nuestro planeta, ¿estaría mejor sin nosotros? ¿Estamos preparados para lo que nos espera?

\section{DE MARZO: EL CONFINAMIENTO}

Son las 7 de la tarde de un jueves normal, mi residente de cuarto año, Marian, y yo estamos finalizando un día de consulta habitual. Justo entonces nos empiezan a llegar whatsapps informándonos de que el alcalde de Igualada, juntamente con otros alcaldes de la Conca de Òdena, comparece por televisión para explicar que se va a 
confinar la Conca, (es decir, la comarca entera), porque hay un brote muy importante de coronavirus. En ese momento no tenemos claro el significado exacto de la palabra confinamiento. Mientras volvía a casa en coche, varias patrullas de la policía autonómica, los Mossos d'Esquadra, me adelantan y bloquean más tarde una salida de Igualada, al lado de mi casa. Ciertamente, esa imagen me impacta y quedará grabada en mi retina para siempre. Igualada permaneció aislada del resto del país durante más de 3 semanas. Esa noche fue la primera de un largo periodo de insomnio.

\section{DE MARZO: LA REALIDAD SUPERA LA FICCIÓN}

Es viernes, Marian y yo tenemos guardia de noche en el Hospital de Igualada. En nuestra zona, los médicos de familia realizábamos las guardias de noche en el Hospital de Igualada atendiendo los niveles IV y $V$ según la escala Andorrana de gravedad. Al empezar la guardia, nos reúne el jefe de Urgencias para explicarnos que ya hay muchos enfermos con covid-19 y que, por lo tanto, tenemos que ponernos los EPI ante cualquier paciente sospechoso de sufrir dicha enfermedad.

El inicio de la guardia es tranquilo; sorprendentemente, atendemos pocas personas con otras enfermedades. A modo de anécdota, los viernes era habitual atender mucha patología traumática leve, ya que era un día de práctica deportiva habitual por parte de los jóvenes de la zona, pero, al estar suspendida toda actividad por el confinamiento, no vimos ningún paciente con lesiones.

Sin embargo, hacia la medianoche empiezan a llegar varias ambulancias con gente mayor proveniente de una residencia de la zona con sospecha de infección por COV-SARS2. A lo largo de la noche continúan viniendo ambulancias con más pacientes, algunos en situación de extrema gravedad. Tres de ellos requieren intubación y se produce una parada cardiorrespiratoria que se remonta.

Recuerdo perfectamente la sensación al acabar la guardia a la mañana siguiente: salir del hospital un sábado a las 8 de la mañana sin nadie en la calle. Pensar que todo aquello no era real. Lo que a priori podía parecer una gripe un poco más grave, era una enfermedad de alta contagiosidad y de evolución rápida, grave, incluso mortal 
en pocas horas, sobre todo en pacientes frágiles. Realmente parecía un plano de cualquier de las muchas películas, hasta ahora fantástica, que preconizan un futuro desolador.

\section{DE MARZO: LA CARPA}

Ya llevamos una semana atendiendo a enfermos con covid-19 en el centro de atención primaria (CAP). Una de las prioridades que nos planteamos es separar la atención covid-19 de la no covid-19; entre otras cosas, para proteger a las personas que acudían al centro por otros problemas de salud, curas, control anticoagulación, etcétera. Inicialmente, aislamos la primera planta del ambulatorio (CAP Anoia) para atender a los pacientes con sospecha de enfermedad por SARS-COV2. En estos momentos ya nos hemos organizado en clave Conca d'Òdena (esta zona engloba los municipios de Igualada, Santa Margarida de Montbui, Vilanova del Camí y Òdena, que suman 70.000 habitantes) y centralizamos toda la atención presencial de adultos en el CAP Anoia. La pediatría, la odontología y el seguimiento del embarazo se atienden en el CAP de Vilanova del Camí, y la consulta telefónica , en el CAP de Santa Margarida de Montbui.

En esos días las personas con clínica compatible con infección por SARSCOV2 es elevada y, para garantizar mejor su atención y a la vez aislar el CAP, con la colaboración del Servicio de Emergencias Médicas de Catalunya (SEM) se instala una carpa delante del CAP Anoia.

\section{DE MARZO: EMPIEZA A FUNCIONAR LA CARPA}

A partir de la tarde del lunes 23, empezamos a visitar en la carpa a los primeros pacientes con sospecha de infección por SAR-COV2 en la carpa. El equipo lo formamos dos profesionales de enfermería y dos médicos, en este caso Marian y yo.

Tenemos sentimientos encontrados: por un lado, estamos emocionados, porque creemos que podremos atender mejor a los pacientes, pero por otro, existe el 
temor de no saber qué nos espera ante una situación absolutamente desconocida.

El funcionamiento que dispusimos fue el siguiente: cuando un paciente acudía al CAP a visitarse, primero lo atendía un administrativo sanitario, que hacia un primer cribado. Si el paciente presentaba sintomatología compatible con infección por COVSARS2, se le dirigía a la carpa. Una vez en el interior, enfermería tomaba las constantes según nuestro protocolo (tensión arterial, frecuencia cardiaca, frecuencia respiratoria, temperatura y saturación de oxígeno). Con esta información ya teníamos una primera aproximación de la situación clínica del paciente y una primera orientación diagnóstica. Si esta última era de sospecha de covid-19, le realizábamos una radiografía simple de tórax y una analítica dirigida a los parámetros afectados por la infección por coronavirus (hemograma, función renal, hepática, LDH, D-dimero, ferritina, ck, troponinas...). Le pusimos el nombre de cli-covid y la pedíamos automáticamente desde el ordenador, porque era la manera de no olvidarnos de nada. En función de los resultados, derivábamos al paciente al hospital o le enviábamos de regreso a su domicilio con seguimiento telefónico programado.

\section{DE MARZO: DESCUBRIMOS LA ECOGRAFÍA PULMONAR}

En el proceso de aprendizaje sobre la covid-19 leímos diversos documentos, que señalaban que la ecografía pulmonar es más sensible en esta enfermedad que la radiología simple de tórax. Tenemos la gran suerte de que en nuestro equipo trabajan dos doctoras, Bea y Laia, con conocimientos y habilidades en el campo de la ecografía pulmonar.

Dicho y hecho, instalamos el ecógrafo del CAP dentro de la carpa y comenzamos a hacer ecografías. Como os podéis imaginar, empezamos la casa por el tejado, ya que en esos momentos todas las ecografías que hacemos son patológicas (línea B confluentes, condensaciones subpleurales, hepatización del pulmón, pulmón blanco...). Al mismo tiempo, como la mayoría de nosotros no teníamos suficientes conocimientos en relación a la ecografía pulmonar, continuábamos haciendo radiografías. Dada la necesidad de aprender, el grupo de trabajo de ecografía en 
Atención Primaria de la Sociedad Catalana de Medicina de Familia(ecoAP) MUY generoso y de una manera totalmente altruista organizaron un curso exprés virtual para los profesionales de la Conca d'Òdena y que finalmente realizamos más de 50 médicos.

\section{DE MARZO: LOS PRIMEROS PROTOCOLOS}

La enfermedad covid-19 nos planteó una situación totalmente nueva: hemos ido aprendiendo sobre la marcha, en el día a día, con la experiencia del momento. Nos ha obligado a afrontar el reto de elaborar nuestros propios algoritmos y guías. A adaptar los protocolos a las peculiaridades de nuestro entorno y nuestro sistema de salud. Hicimos documentos que se tenían que actualizar continuamente en función de la evidencia científica del momento. Esas primeras semanas fueron, además, de lectura y estudio intenso diario, de compartir ideas, de propuestas entre nosotros (medicina, enfermería, atención al usuario, farmacia, direcciones, etcétera).

Agradecimiento para todos los compañeros implicados en la elaboración y revisión de los protocolos, circuitos y algoritmos, por las horas dedicadas. $\mathrm{Y}$, en especial, a la Mar, farmacéutica del Servicio de Atención Primaria del Anoia.

A pesar de todo y de la gravedad de la situación, para mí ha sido una experiencia intelectual muy enriquecedora y considero que es bueno quedarse con esa sensación.

\section{FINALES DE MARZO Y PRINCIPIOS DE ABRIL: CUMPLEAÑOS Y SEMANA SANTA}

Son días muy difíciles. Estamos atendiendo una media de 60-70 pacientes al día con sospecha de enfermedad por SARS-COV2. En esos momentos el diagnóstico era clínico, ya que en la carpa no disponíamos de PCR. La mayoría de los pacientes presentaban afectación pulmonar grave. Llegué a calcular que derivábamos al hospital al $80 \%$ de pacientes, de los que ingresaban prácticamente todos.

Otro recuerdo impactante es la atención domiciliaria de aquellos momentos, pacientes graves que, por sus características, lo mejor que podíamos hacer era 
atención en el propio domicilio del final de vida. Se certificaban 6 o 7 defunciones diarias. Acompañábamos a las familias lo mejor posible, pero vestidos con los EPI no era la mejor manera.

Pienso muy a menudo en el acompañamiento en el duelo a una viuda cogiéndole la mano con doble guante, dentro de la carpa. A menudo llorábamos a solas, fue realmente duro.

Llegaba a casa agotado, pero con la sensación de que lo estábamos haciéndo lo mejor que podíamos y sabíamos, en aquel momento tan difícil.

Fue un intenso día de atención domiciliaria. Al llegar la tarde mi residente de primer año, Carol, empezó a encontrarse mal. Primero pensamos que era emocional, que estaba cansada, pero por desgracia se confirmaron nuestros temores: había enfermado por coronavirus (fiebre, dolor torácico, hiposmia, ageusia...), en la ecografía había una pequeña infiltración unilateral, por suerte es una chica fuerte y se ha recuperado por completo.

En esos días hay varios eventos que quisiera destacar. Como los cumpleaños de Marian, (hizo los 30 el 27 de marzo) y mío propio, (3 de abril). Los dos se celebraron dentro de la ya famosa carpa. Aunque no fuese la manera ideal de festejar el aniversario, recuerdo el mío con cariño. Mi última residente, Laia, que ahora es compañera de trabajo del CAP, y Marian, me prepararon una sorpresa con globos, magdalenas y velas de mis i¡50 años!!, con video incluido para el recuerdo.

Otro evento que quedará para el recuerdo es la Semana Santa del 2020. En mi caso, la familia me había organizado un viaje para conmemorar mi mitad de siglo. Evidentemente, se tuvo que cancelar, ya que la situación me obligó a trabajar como si de una semana normal se tratara. Sin embargo, la verdad es que a posteriori el sentimiento que queda es el de misión cumplida.

\section{DE ABRIL: VOLVEMOS AL CAP}

Los días previos al 16 de abril fueron climatológicamente inestables, alternando días de tormentas con otros muy calurosos. En cambio, la situación provocada por la 
covid-19 parecía más controlada, dado que los nuevos casos se habían estabilizado y eran menos graves. Por esos motivos se decidió desmontar la carpa instalada en los exteriores del CAP y volver a la primera planta del ambulatorio.

\section{DE ABRIL: UN SANT JORDI DIFERENTE}

El 23 de abril es el día de Sant Jordi, probablemente la festividad más emblemática de Catalunya. En un año normal las calles se hubieran llenado de puestos vendiendo rosas. En el centro de la ciudad, las librerías hubieran montado paradas con multitud de libros. No en vano el día de Sant Jordi es el del libro y la rosa. En esta ocasión fue un Sant Jordi sin rosas, ni libros, ni gente por las calles, pero aun así tuvimos gratas sorpresas. Una entidad de la ciudad que trabaja con y para personas con minusvalía física y/o mental nos regaló rosas de fieltro rojo hechas por ellos mismos con un lema muy claro "Por Sant Jordi nos quedamos en casa".

Otra sorpresa fue un vídeo de agradecimiento a los profesionales de la salud que gravó un paciente de una compañera del equipo.

Sin duda fue un Sant Jordi diferente.

\section{DE ABRIL: VIENE, PERO PARA IRSE, LA HIDROXICLOROQUINA}

Los profesionales de la atención primaria nos sentíamos limitados, ya que no se nos era permitido prescribir tratamiento específico para el SARS-COV2. EI tratamiento estandarizado entonces para proporcionar a nivel comunitario era la hidroxicloroquina(HCQ). Se producía el contrasentido de que si el paciente era visitado en Urgencias del hospital y recibía el alta con el diagnóstico de neumonía leve por coronavirus, se le podía prescribir HCQ a domicilio. En cambio, si ese mismo paciente era visitado en un servicio de atención primaria (AP), el profesional que lo visitaba no podía prescribirla. Después de reunirnos con los responsables, pudimos desencallar la situación y elaboramos nuevamente un protocolo/algoritmo de actuación muy concreto (neumonía unilateral, sin signos de gravedad ni comorbilidades) para poder prescribir 
HCQ desde la AP. Por desgracia para todos, nuestro gozo en un pozo, ya que los estudios demostraron que la HCQ no tenía eficacia en el tratamiento de la covid-19.

\section{DE MAYO: LLEGAN LAS PCR}

Dos meses después del inicio de la pandemia, en Igualada podemos realizar en la AP la PCR a los pacientes con sospecha diagnóstica. Nuestra alegría es evidente, aunque ya nos coge un poco agotados. En esos momentos los casos han disminuido de manera importante, pero la posibilidad de realizar la PCR nos permite, al menos, hacer un mejor diagnóstico y seguimiento epidemiológico más adecuado.

Quiero mencionar que la actitud de la población siempre ha sido excepcional. Aunque muchas veces la información recibida no era la que se quería escuchar. $Y$ nosotros no siempre podíamos explicarnos como queríamos, porque la situación era tan cambiante que en ocasiones generaba informaciones contradictorias.

\section{DE MAYO: SEGUIMIENTO POST-ALTA Y PRIMERA ECOGRAFÍA A DOMICILIO}

Llevamos ya días visitando a pacientes dados de alta de los hospitales de referencia de nuestra zona. Otra vez, entre todos elaboramos un protocolo para atender a los pacientes post-alta (seguimiento telefónico, analítica de control, visita presencial y ecografía pulmonar). Por suerte, la mayoría de pacientes salen de alta curados de la enfermedad, algunos, la minoría, requieren seguimiento por parte del equipo de neumología, con el cual también nos reunimos esos días a fin de ver cómo nos organizamos para que no se deje de visitar a ningún paciente, sobre todo por el riesgo de desarrollar fibrosis pulmonar. Dicho lo dicho, también nos encontramos con pacientes que, debido a la gravedad de la enfermedad y de que han pasado semanas ingresados, incluso durante meses (intubados en $\mathrm{UCl}$ ) se hallan en una situación de extremada fragilidad y requieren ser visitados a domicilio. Gracias a la donación por parte de Colegio Oficial de Médicos de Barcelona, disponemos de un ecógrafo portátil y podemos realizar ecografías en el propio domicilio a dos pacientes. 
Son días en que emocionalmente estamos un poco mejor. Los pacientes que han recibido el alta del hospital están contentos y agradecidos, con el sentimiento general de que tienen una segunda oportunidad de seguir viviendo. Lo han pasado francamente mal, sin sus seres queridos y con el pensamiento de que la situación por la que han atravesado podía ser la última de sus vidas.

La incidencia de la enfermedad por coronavirus desciende de manera muy importante, aunque continuamos viendo casos aislados y mucho más leves. Esta situación nos permite reorganizar las agendas y empezar a visitar a nuestros pacientes habituales. Son días de reencuentro con personas queridas tras años de seguimiento. Por desgracia, también son días de otros diagnósticos, ya lo sabíamos, no todo es COVSARS2.

\section{DE JULIO: TESTS SEROLÓGICOS RÁPIDOS}

La directora nos informa de que disponemos de los test serológicos rápidos IgM e lgG. Inicialmente los utilizamos para saber la situación inmunológica de los pacientes que habíamos diagnosticado solo clínicamente en los meses que no disponíamos de PCR ni serologías. Es una buena noticia para nosotros y para la población, ya que nos permite saber el estado inmunitario de muchas personas que atendimos en la Atención Primaria en lo peor de la pandemia y no les pudimos hacer pruebas diagnósticas en aquel momento.

En julio, por fin me puedo coger unos días de vacaciones: los paso en el Cap de Creus con mi esposa, Mònica, mis hijos, Olau e Íria, y cómo no, con Bru, el perro Shar-pei, mascota de la familia. Sin ellos no hubiera podido sobrevivir durante estos meses de trabajo intenso de lunes a domingo, de noches de insomnio, de horas de estudio, de confinamiento... 


\section{DE JULIO: EL DÍA DE LA MARMOTA}

17 de julio de 2020, son las tres de la tarde. Hoy he pasado mi consulta de la nueva normalidad compuesta por atención telefónica, consultas virtuales y alguna visita presencial. Realmente, me está resultando difícil adaptarme a esta nueva manera de atender a mis pacientes, pero si algo hemos demostrado los profesionales de la salud en esta pandemia es nuestra resiliencia.

Estamos finalizando la reunión de equipo de cada viernes donde ponemos en común las dificultades de la semana y comentamos cómo se prevén los próximos días, a la vez que deseamos buenas vacaciones a aquellos que las empiezan. Es en ese momento cuando nos llega a todos un mensaje por el grupo de médicos de whatsapp: la compañera que está de guardia visitando pacientes con sospecha de coronavirus nos informa de que acaba de enviar al hospital a una mujer de 44 años con fiebre, malestar general, tos de una semana de evolución y en la ecografía líneas B confluyentes en múltiples campos pulmonares. En ese instante, no puedo hacer otra cosa que pensar en el día de la marmota...

\section{Francesc Xavier Cantero Gómez}

Médico y Tutor de Medicina Familiar y Comunitaria del Equipo de Atención Primaria Igualada Urbà. Màster de Atención Primaria por la Universidad de Barcelona.

Vicepresidente del Comité de Ética Asistencial del Anoia.

\section{Cómo citar este artículo:}

Cantero Gómez, F.X., "Cuaderno de bitácora Covid-19. Igualada 2020", Folia Humanística, 2020; 3(2): 60-69. Doi: http://doi.org/10.30860/0070

(C) 2020 Todos los derechos reservados a la Revista Folia Humanística de la Fundación Letamendi Forns. This is an open access article. 